\title{
Pyramiding Unmarked Deletions in Ralstonia solanacearum Shows That Secreted Proteins in Addition to Plant Cell-Wall-Degrading Enzymes Contribute to Virulence
}

\author{
Huanli Liu, ${ }^{1}$ Shuping Zhang, ${ }^{1}$ Mark A. Schell, ${ }^{2}$ and Timothy P. Denny ${ }^{1}$ \\ Departments of ${ }^{1}$ Plant Pathology and ${ }^{2}$ Microbiology, The University of Georgia, Athens, Georgia 30602, U.S.A.
}

Submitted 9 June 2005. Accepted 25 August 2005.

Ralstonia solanacearum, like many phytopathogenic bacteria, makes multiple extracellular plant cell-wall-degrading enzymes (CWDE), some of which contribute to its ability to cause wilt disease. CWDE and many other proteins are secreted to the milieu via the highly conserved type II protein secretion system (T2SS). $R$. solanacearum with a defective T2SS is weakly virulent, but it is not known whether this is due to absence of all the CWDE or the loss of other secreted proteins that contribute to disease. These alternatives were investigated by creating mutants of wild-type strain GMI1000 lacking either the T2SS or up to six CWDE and comparing them for virulence on tomato plants. To create unmarked deletions, genomic regions flanking the target gene were polymerase chain reaction (PCR)-amplified, were fused using splice overlap extension PCR, were cloned into a suicide plasmid harboring the $s a c B$ counter-selectable marker, and then, were site-specifically introduced into the genome. Various combinations of five deletions $(\triangle p e h A, \Delta p e h B, \Delta p e h C$, $\Delta p m e$, and $\Delta e g l)$ and one inactivated allele $(\operatorname{cbh} A:: a p h A-$ 3) resulted in 15 mutants missing one to six CWDE. In soil-drench inoculation assays, virulence of mutants lacking only pectic enzymes (PehA, PehB, PehC, and Pme) was not statistically different from GMI000, but all the mutants lacking one or both cellulolytic enzymes (Egl or CbhA) wilted plants significantly more slowly than did the wild type. The GMI-6 mutant that lacks all six CWDE was more virulent than the mutant lacking only its two cellulolytic enzymes, and both were significantly more virulent than the T2SS mutant (GMI-D). Very similar results were observed in wounded-petiole inoculation assays, so GMI-6 and GMI-D appear to be less capable of colonizing tomato tissues after invasion. Because the T2SS mutant was much less virulent than the sixfold CWDE mutant, we conclude that other secreted proteins contribute substantially to the ability of $R$. solanacearum GMI1000 to systemically colonize tomato plants.

Many microorganisms produce extracellular plant cell-walldegrading enzymes (CWDE). The CWDE of plant pathogens have long been studied due to their obvious potential in pro-

Corresponding author: T. P. Denny; E-mail: tdenny@uga.edu; Telephone: +1.706 .542 .1282 ; Fax: +1.706.542.1262.

Current address for S. Zhang: Department of Biological Sciences and Biotechnology, Tsinghua University, Beijing, 100084, P. R. China. moting pathogenesis and causing disease symptoms. This line of research is exemplified by the extensive work with Pectobacterium carotovora and Erwinia chrysanthemi that elucidated many aspects of the biochemistry and genetics of CWDE relevant to soft-rot diseases (Toth et al. 2003). Maceration of living plant tissues by these pathogens is primarily due to the activity of one or more basic pectate lyase (Pel) exoenzymes. Some of the other CWDE contribute to disease in more subtle ways, possibly by more precise destruction of cell-wall components or by generating signal molecules that may be recognized by either the plant or the pathogen.

CWDE are also known to contribute to disease caused by Ralstonia solanacearum, a soil-borne, gram-negative bacterium that can wilt more than 200 plant species in 50 families (Hayward 2000; Schell 2000). Important hosts of $R$. solanacearum include tomato, potato, tobacco, geranium, and banana, and it routinely causes significant yield losses in commercial and subsistence agriculture world-wide. $R$. solanacearum normally invades plant roots via wounds or where secondary roots emerge, penetrates the xylem, and then, systemically colonizes the vascular system. Extensive colonization disrupts vascular function and the plants rapidly wilt and die. It is only during the later stages of the disease that nonwoody stem tissue is obviously macerated.

The involvement of $R$. solanacearum CWDE has been examined in strains AW and K60, usually with tomato or eggplant as the host (Denny et al. 1990; González and Allen 2003; Huang and Allen 1997). These very similar strains both produce five exoenzymes: one $\beta$-1,4-endoglucanase (Egl), one endopolygalacturonase (PehA or PglA), two exopolygalacturonases (PehB and PehC), and a pectin methyl esterase (Pme). $R$. solanacearum is not known to produce any Pel enzymes. Genetic inactivation of single genes has shown that none of the five exoenzymes is essential for disease, but that Egl, PehA, and PehB each contribute to the wild-type's ability to cause wilt, with PehB being the least important (Denny et al. 1990; Huang and Allen 2000). The absence of PehC or Pme individually has no effect on virulence (González and Allen 2003; Tans-Kersten et al. 1998). The effect of eliminating two enzymes (either Egl PehA or PehA PehB) is additive, but the double mutants still wilt at least $50 \%$ of the leaves within two weeks after inoculation (Denny et al. 1990; Huang and Allen 2000). Surprisingly, elimination of all three Peh enzymes resulted in a mutant that was more virulent than the PehA PehB double mutant, a result that González and Allen (2003) speculated was due to the absence of pectic breakdown products that stimulate plant defenses. 
In gram-negative bacteria, most extracellular proteins (EXP) transit the inner membrane via Sec-dependent general export pathways and the outer membrane via the type II secretion system (T2SS). Inactivation of the T2SS results in proteins that normally are secreted accumulating in the periplasm or cytoplasm and, in the case of Xanthomonas campestris and Erwinia chrysanthemi mutants, loss of pathogenicity (Dums et al. 1991; Lindeberg and Collmer 1992). Similarly, Kang and associates (1994) created a putative T2SS mutant of $R$. solanacearum AW and found that it multiplied poorly in tomato stems and did not cause wilt symptoms. This mutant was later confirmed to have a defective T2SS, because DNA sequencing showed that it has Tn5 inserted into $s d p M$, which encodes an essential inner membrane component of this secretion system (T. P. Denny, unpublished data). These results indicate that, in many cases, the panoply of EXP or, more likely, some subset of EXP is critical for pathogenesis, but they provide no clues as to which proteins are responsible.

Investigating the role of all the known CWDE is challenging, because there are more loci to inactivate than there are antibiotic resistance markers useful for standard allelic replacement. Also, a cell that constitutively expresses resistance to multiple antibiotics may not behave normally. Simultaneous elimination of multiple genes, or deletion pyramiding, requires that unmarked deletions be site-specifically created in target loci. Several gene-specific mutagenesis methods that introduce unmarked deletions have been described for bacteria (Reyrat et al. 1998; Muyrers et al. 2001), but the most common strategy employs $s a c B$, the Bacillus subtilis levansucrase gene, as a counter-selectable marker to eliminate the large majority of nonmutant cells. We report here the facile pyramiding of unmarked mutations in $R$. solanacearum GMI1000, whose genomic sequence has been determined (Salanoubat et al. 2002), to investigate whether the low virulence of a T2SS mutant can be explained by the loss of all known CWDE or if other EXP are involved.

\section{RESULTS}

\section{Identification and inactivation}

of the type II secretin in $R$. solanacearum.

The highly conserved type II secreton comprises 12 to 15 proteins, most of which are within or associated with the inner membrane (Delepelaire and Wandersman 2001; Desvaux et al. 2004; Sandkvist 2001). One protein, a member of the secretin family, forms a ring-shaped oligomeric complex in the outer membrane through which mature, folded proteins are secreted (Delepelaire and Wandersman 2001). To make a T2SS mutant of $R$. solanacearum GMI1000, we targeted the putative secretin protein encoded by locus RSc3114, which is embedded in a cluster of 12 putative genes that are very similar to those encoding well-characterized T2SSs. The putative presecretin is predicted to be processed to a 767-amino acid mature protein whose C-terminal half has significant alignment with Secretin $\mathrm{C}\left(\right.$ PFAM00263; $\left.\mathrm{E}=2 \times 10^{-49}\right)$ and PulD (COG1450; $8 \times 10^{-73}$ ) conserved domains; it also contains the T2SS protein D signature (Prosite PDOC00683). We will refer to locus RSc3114 as $s d p D$ (secreton-dependent pathway D) (Desvaux et al. 2004) and the protein it encodes as $\mathrm{SdpD}_{\text {Rsol }}$.

We inactivated $s d p D$ in the genome of GMI1000 by homologous recombination with a suicide plasmid carrying an internal fragment of this gene, which resulted in two partial copies of $s d p D$. This insertion may also have polar effects, eliminating expression of up to two $s d p$ genes downstream. A representative mutant, GMI-D, was selected, and as expected, it made little or no detectable exoenzyme activity on enzyme assay plates (Fig. 1A). The slight Peh activity is presumably due to leakage of one or more isozymes from the periplasm. Analysis of concentrated culture supernatants by sodium dodecyl sulfate-polyacrylamide gel electrophoresis (SDS-PAGE) revealed that the majority of EXP made by GMI1000 are not secreted by GMI-D (Fig. 1B), but at least two lower-molecular-mass proteins (approximately 11 and $17 \mathrm{kDa}$ ) are secreted in wild-type amounts. The multiplication rates of GMI1000 and GMI-D were comparable in both modified Bacto peptoneyeast (MBG) and liquid minimal medium (MM) (not shown).

\section{Cellobiohydrolase A $(\mathrm{CbhA})$ is a potential CWDE.}

The genes encoding five known $R$. solanacearum CWDE were identified in the genome of GMI1000 (Table 1), based on their near identity to homologs in strains AW and K60. We investigated whether GMI1000 may encode additional CWDE
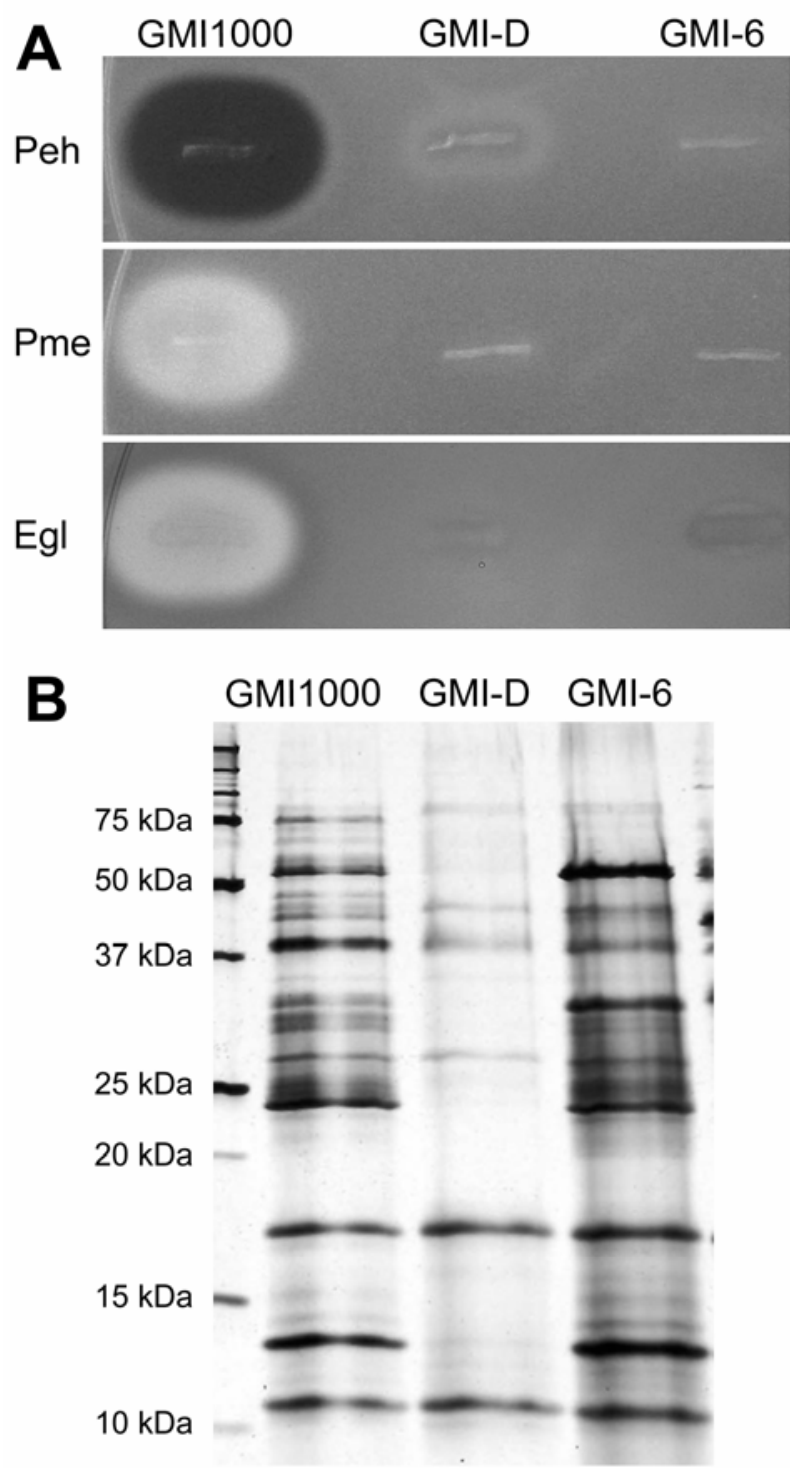

Fig. 1. Extracellular proteins produced by Ralstonia solanacearum GMI1000 (wild type), GMI-D (sdpD::pTok2), and GMI-6 ( $\Delta p e h A \Delta p e h B$

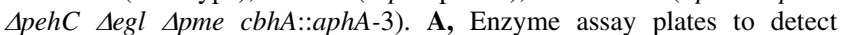
activity of endopolygalacturonase (Peh) (clear zone on a hazy white background), pectin methyl esterase (Pme) (hazy white zone on a clear background), or $\beta$-1,4-endoglucanase (Egl) (yellow zone on a red background). B, extracellular proteins recovered from the supernatants of minimal medium liquid cultures ( $1.5 \mu \mathrm{g}$ of each sample) were resolved by sodium dodecyl sulfate-polyacrylamide gel electrophoresis (15\% acrylamide) and were stained with silver. Molecular mass standards are in the partial lane at the far left. 
and found that, of the 77 open reading frames (ORF) that may encode carbohydrate active enzymes (CAZy website [Coutinho and Henrissat 1999]), the only strong candidate is locus RSp0583, annotated as a probable 1,4- $\beta$-cellobiohydrolase. Inspection suggested a better translational start site for this ORF 12 codons downstream from that currently annotated (Table 1), resulting in a protein with 561 amino acids that are 75\% identical to COG5297:cellobiohydrolase A $(E=0.0)$. The National Center for Biotechnology Information Conserved Domain Database also predicts the presence of a glycosyl hydrolase $(\mathrm{GH})$ family 6 catalytic domain, including both signature sequences and a type II carbohydrate-binding module (Fig. 2). Analysis using SignalP 3.0 (Bendtsen et al. 2004) strongly suggested the presence of a signal peptide (residues 1 through 35 ), and the predicted mature protein was detected among GMI1000 EXP resolved on one- and two-dimensional polyacrylamide gels using, respectively, N-terminal amino acid sequencing (J. A. McGarvey and M. A. Schell, unpublished results) and peptide mass fingerprint analysis (T. P. Denny and H. Liu, unpublished results).

A BLAST search (Altschul et al. 1997) revealed that the Nterminal 435 amino acids of the $R$. solanacearum mature protein are $56 \%$ identical to the comparable $\mathrm{GH}$ family 6 region of the well-characterized CbhA from Cellulomonas fimi (Meinke et al. 1994). This enzyme releases cellobiose from the nonreducing end of 1,4- $\beta$-D-glucans, so it is also called an exoglucanase. These two proteins are also similar in their carbohydrate-binding module ( $28 \%$ identical), but the $R$. solanacearum protein lacks the three fibronectin type III regions present in the $C$. fimi CbhA (Fig. 2). Hereafter, we will refer to $R$. solanacearum locus RS03897 as cbhA and the protein it encodes as $\mathrm{CbhA}_{R s o l}$, and we included it as a potential sixth CWDE made by $R$. solanacearum to be targeted for elimination.

\section{Creating mutants lacking one to six CWDE.}

Plasmid-borne 'deletion alleles' were created for the five known CWDE by introducing six nucleotides with the SpeI restriction endonuclease site between approximately 500-bp fragments amplified from near the ends of each target ORF. Two-step, SacB-assisted mutagenesis (discussed below) sitespecifically replaced each wild-type gene with its deletion allele and removed the vector DNA. $c b h A$ was inactivated by inserting an aphA-3 cassette, because it was advantageous to have one antibiotic resistance marker in the sixfold mutant. These mutations are not expected to have polar effects because the deletion alleles were designed to not interfere with expression of downstream genes, each of which appears to be transcribed from its own promoter.

The 15 mutants that lack from one to six CWDE are described in Figure 3. The six mutants (GMI-11 to GMI-16) with individual mutations ( $\triangle p e h A, \Delta p e h B, \Delta p e h C, \Delta e g l, \Delta p m e$, or cbhA::aphA-3, respectively) were constructed first. Either enzyme assay plates, PCR analysis, or both showed the fidelity of the site-specific gene replacements (not shown). Various combinations of one to five additional mutations then were introduced during sequential cycles of mutagenesis, ending with GMI-6, the sixfold mutant (the order of gene inactivation in GMI-6 was pehB, pehA, pehC, egl, pme, cbhA). PCR analysis of genomic DNA using gene-specific primers showed that each target locus in GMI-6 had the expected change in size (Fig. 4). In addition, each approximately 1-kb fragment amplified from the five deletions in GMI-6 could be digested with SpeI, indicating the presence of the synthetic DNA that replaced the ORF (not shown). Enzyme assay plates showed that GMI-6 produced no detectable Peh, Pme or Egl activity (Fig. 1A). There was no detectable $\mathrm{CbhA}_{\text {Rsol }}$ activity produced by GMI14 , using enzyme assay plates containing carboxymethylcellulose. When $10 \times$ concentrated culture supernatant of GMI-14 $(\Delta e g l)$ was incubated with carboxymethylcellulose for up to 4 $\mathrm{h}$, there was a very slight color change in the assay tubes, but we are not confident this was due to $\mathrm{CbhA}_{\text {Rsol }}$ activity (not shown). Analysis of GMI-6 concentrated culture supernatant

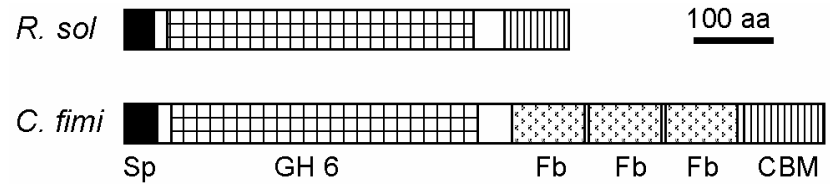

Fig. 2. Organization of functional modules in Ralstonia solanacearum and Cellulomonas fimi cellobiohydrolase A enzymes (NP 522144 and AAC36898, respectively). Module abbreviations are: Sp, signal peptide; GH 6, glycosyl hydrolase 6 domain; $\mathrm{Fb}$, fibronectin type III domain; CBM, carbohydrate binding module type II. The GH 6 module in $R$. solanacearum can be aligned with $99.6 \%$ of PFAM01341 (E value $=2 \times$ $10^{-47}$ ) and the CBM can be aligned with $83.2 \%$ of Smart00637 (E value $=$ $\left.8 \times 10^{-12}\right)$

Table 1. Strains, plasmids, and gene targets used to initiate this study

\begin{tabular}{|c|c|c|}
\hline $\begin{array}{l}\text { Strain, plasmid, or } \\
\text { gene target }\end{array}$ & Relevant information $^{a}$ & Reference or source \\
\hline \multicolumn{3}{|l|}{ Strains } \\
\hline Escherichia. coli & & \\
\hline DH5 $\alpha$ & 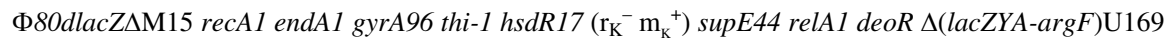 & Invitrogen \\
\hline \multicolumn{3}{|c|}{ Q } \\
\hline GMI1000 & Wild-type; race 1 , biovar 3 , phylotype I; $\mathrm{Tfp}^{+} \mathrm{Twt}^{+} \mathrm{Pil}^{+} \mathrm{HR}^{+}$ & Salanoubat et al. 2002 \\
\hline \multicolumn{3}{|c|}{ 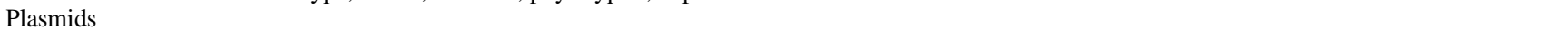 } \\
\hline pGEM-T Easy & T-A cloning vector for polymerase chain reaction (PCR) fragments, $\mathrm{Ap}^{\mathrm{r}}$ & Promega \\
\hline pCR2.1 & T-A cloning vector for PCR fragments, $\mathrm{Km}^{\mathrm{r}}$ & Invitrogen \\
\hline pTOK2 & Narrow host-range cloning vector, $\mathrm{Tc}^{\mathrm{r}}$ & Kitten and Willis 1996 \\
\hline pEX18Tc & oriT $^{+} \operatorname{sacB}^{+}$, gene-replacement vector, $\mathrm{Tc}^{\mathrm{r}}$ & Hoang et al. 1998 \\
\hline pUC18K & Source of aphA-3 cassette, $\mathrm{Ap}^{\mathrm{r}} \mathrm{Km}^{\mathrm{r}}$ & Menard et al. 1993 \\
\hline \multicolumn{3}{|l|}{ Gene Targets } \\
\hline pehA & Endo-polygalacturonase (E.C. 3.2.1.15) & NP_522441 \\
\hline $\operatorname{peh} B$ & Exo-poly- $\alpha$-galacturonosidase (E.C. 3.2 .1 .82 ) & NP_519877 \\
\hline pehC & Galacturan 1,4- $\alpha$-galacturonidase (exopolygalacturonase; E.C. 3.2.1.67) & NP_522394 \\
\hline pme & Pectin methylesterase (E.C. 3.1.1.11); proposed CDS is complement $160019 . .161209$ & NP_521699 \\
\hline egl & $1,4-\beta$-endoglucanase (E.C. 3.2.1.4) & NP 521723 \\
\hline $\operatorname{cbh} A$ & 1,4- $\beta$-cellobiohydrolase (exoglucanase; E.C. 3.2.1.91); proposed CDS is $718291 . .71994$ & NP_522144 \\
\hline$s d p D$ & Type II secretion pathway protein D (outer membrane secretin) & NP 521235 \\
\hline
\end{tabular}

${ }^{\mathrm{a}} \mathrm{Twt}=$ twitching motility, Tfp = type IV pili, Pil = Hrp pili, HR = hypersensitive response on tobacco, CDS = coding sequence. Ralstonia solanacearum phylotype as proposed by Fegan and Prior (2005). $\mathrm{Ap}^{\mathrm{r}}, \mathrm{Km}^{\mathrm{r}}, \mathrm{Tc}^{\mathrm{r}}=$ ampicillin, kanamycin, and tetracycline resistant, respectively. 
by SDS-PAGE revealed that it has almost all the other proteins secreted by GMI-1000 (Fig. 1B).

\section{GMI1000 and the CWDE mutants} are otherwise indistinguishable.

To check whether the cycles of mutagenesis had unintended side effects, we compared GMI000 and the $15 \mathrm{CWDE}$ mutants for other traits known to affect virulence. The multiplication rate of all the strains was the same when cultured in MBG broth; GMI1000 and GMI-6 also multiplied equally well when cultured in liquid MM. All the strains produced comparable quantities of extracellular polysaccharide in shaken broth culture and qualitatively similar biofilms developed in static broth culture. All the strains exhibited comparable twitching and swimming motility in culture, indicating normal production of type IV pili and flagella. All the strains induced the hypersensitive response when tobacco leaves were infiltrated with $1 \times$ $10^{7} \mathrm{CFU} \mathrm{m}{ }^{-1}$ of cells, showing that they retained a functional Hrp type III protein secretion system.

\section{Wild-type virulence requires both cellulolytic enzymes and unknown EXP.}

GMI1000, GMI-D, and each of 15 CWDE mutants were tested for virulence on tomato in three to six independent experiments using soil drench inoculation (Fig. 5A and B). GMI1000 wilted and killed all 63 inoculated plants in less than 12 days, and the mutants lacking one to six CWDE wilted more than $80 \%$ of the leaves and colonized over $99 \%$ of 531 plants by day 15 , when the assays were terminated. In contrast, GMI-D wilted about $19 \%$ of the leaves and colonized the lower stem of only $52.8 \%$ (range from 30 to $80 \%$ in five experiments) of the 53 plants. Statistical analysis using a proportional hazards survival model showed that GMI-D was significantly less virulent than GMI1000 $(P<0.0001)$ and all of the CWDE mutants $(P<0.05)$.

Mutants lacking only pectic enzymes (Peh, Pme, or both; Fig. 5A) were statistically indistinguishable from their parent strain GMI000, but they were more virulent $(P<0.05)$ than the mutants lacking one or both cellulolytic enzymes (Egl and $\mathrm{CbhA}_{R s o l}$; Fig. 5B). There were several consistent trends in

\begin{tabular}{|c|c|c|c|c|c|c|}
\hline \multirow[b]{2}{*}{ Strain } & \multicolumn{6}{|c|}{ Enzyme Eliminated } \\
\hline & PehA & PehB & PehC & Egl & Pme & CbhA \\
\hline GMI-11 & $\varnothing$ & & & & & \\
\hline GMI-12 & & $\varnothing$ & & & & \\
\hline GMI-13 & & & $\varnothing$ & & & \\
\hline GMI-14 & & & & $\varnothing$ & & \\
\hline GMI-15 & & & & & $\varnothing$ & \\
\hline GMI-16 & & & & & & $\varnothing$ \\
\hline GMI-21 & $\varnothing$ & $\varnothing$ & & & & \\
\hline Gml-22 & $\varnothing$ & & & $\varnothing$ & & \\
\hline GMI-23 & & & & $\varnothing$ & & $\varnothing$ \\
\hline GMI-31 & $\varnothing$ & $\varnothing$ & $\varnothing$ & & & \\
\hline GMI-32 & $\varnothing$ & $\varnothing$ & & $\varnothing$ & & \\
\hline GMI-41 & $\varnothing$ & $\varnothing$ & $\varnothing$ & & $\varnothing$ & \\
\hline GMI-42 & $\varnothing$ & $\varnothing$ & $\varnothing$ & $\varnothing$ & & \\
\hline GMI-5 & $\varnothing$ & $\varnothing$ & $\varnothing$ & $\varnothing$ & $\varnothing$ & \\
\hline GMI-6 & $\varnothing$ & $\varnothing$ & $\varnothing$ & $\varnothing$ & $\varnothing$ & $\varnothing$ \\
\hline
\end{tabular}

Fig. 3. Fifteen Ralstonia solanacearum mutants that are missing from one to six extracellular plant cell-wall-degrading enzymes. All genes were eliminated by site-specifically creating unmarked deletions except for $c b h A$, which was inactivated by insertion of an $a p h A-3$ gene cassette. virulence among the pectic enzyme mutants. First, the absence of Pme had virtually no effect on any mutant (compare GMI1000 to GMI-15 and GMI-31 to GMI-41). Second, mutants missing one Peh enzyme (GMI-11, GMI-12, and GMI13) were all slightly less virulent than GMI1000. Third, elimination of a second (GMI-21, PehB/C $\mathrm{C}^{-}$) and, especially, a third (GMI-31, PehA/B/C ${ }^{-}$) Peh enzyme consistently increased virulence to the level of GMI1000 or better.

The mutants lacking only one or both cellulolytic enzymes were significantly less virulent than GMI1000 $(P<0.0001)$, with the loss of Egl (GMI-14) having a greater effect than loss of $\mathrm{CbhA}_{\text {Rsol }}(\mathrm{GMI}-16)$ (Fig. 5B). Elimination of both enzymes appeared to be additive and resulted in GMI-23 being significantly less virulent than any other CWDE mutant $(P<0.05)$. The combined loss of cellulolytic enzymes and one or more Peh enzymes always resulted in enhanced virulence. This pattern was most apparent when comparing GMI-6, which lacks all six CWDE, and GMI-23, which only lacks Egl and $\mathrm{CbhA}_{R s o l}$ activities. A smaller increase in virulence was observed when comparing mutants missing only Egl (GMI-14) and mutants that also lacked one (GMI-22), two (GMI-32), or three (GMI42 and GMI-5) Peh enzymes.

GMI1000, GMI-D, and GMI-6 also were compared using a wounded-petiole inoculation method in three separate experiments (Fig. 6). Except for the slightly delayed onset of initial wilt symptoms, the rate at which plants wilted after petiole inoculation was very similar to that observed after soil-drench inoculation (Fig. 5A and B). Statistical analysis showed that the virulence of each strain was significantly different $(P<$ 0.0001 ) from the other two.

\section{DISCUSSION}

This paper reports the most thorough investigation of the contribution of plant CWDE in bacterial wilt disease caused by $R$. solanacearum. Previous research employed mutants created by transposon mutagenesis or site-specific inactivation of up to three target genes by insertion of different antibiotic resistance cassettes. Use of these marked mutants was satisfactory in the past, but years of research and the recent availability of the GMI1000 sequence provided a set of genes that could only be studied in toto by pyramiding multiple unmarked mutations.

Interest in making unmarked mutants has increased with the recent development of methods combining bacteriophage lambda and yeast Flp-FRT recombinase systems (Datsenko and Wanner 2000; Murphy and Campellone 2003; Schweizer 2003). These methods work well for enteric bacteria, but they

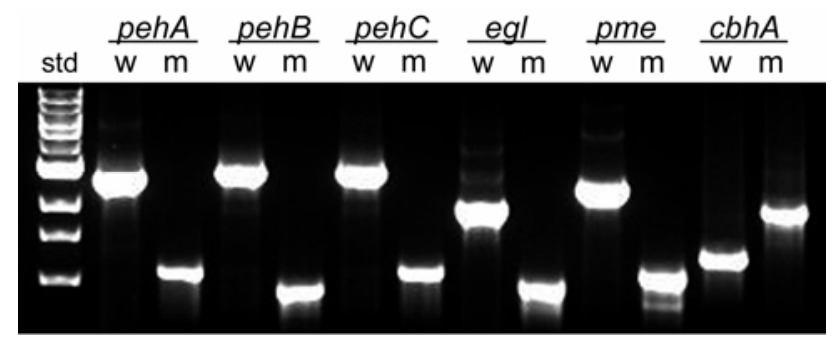

Fig. 4. Polymerase chain reaction (PCR) analysis of all target loci in Ralstonia solanacearum GMI1000 and GMI-6 (ApehA $\Delta p e h B \Delta p e h C \Delta e g l$ $\Delta p m e$ cbhA::aphA-3). Six pairs of PCR reactions were run, using genomic DNA from GMI1000 (w) and GMI-6 (m), plus the SOE1 and SOE4 primers for each target gene. The amplicon from each of the five deleted gene targets in GMI-6 was smaller than from the wild-type loci. The amplicon from $c b h A:: a p h A-3$ is larger than that from the wild type due to the inserted antibiotic gene cassette. The size standard (std) was a 1-kb DNA ladder (New England Biolabs). 
are still being adapted for use in other species, and our attempt to alter the popular system of Datsenko and Wanner (2000) for use in GMI1000 was unsuccessful. In addition, these methods have rarely been used for pyramiding mutations, possibly because the FRT 'scars' that remain after each deletion event can lead to inversions or deletions between these sites (Muyrers et al. 2001; Schweizer 2003).

To make $R$. solanacearum unmarked mutants, we adapted the most common strategy that employs the $s a c B$ counterselectable marker and two separate cycles of homologous recombination. The first cycle introduces the deletion allele and the suicide plasmid vector into the genome, and the second cycle eliminates the vector and deletes the targeted gene. This approach is sometimes plagued by a high rate of spontaneous mutations in $s a c B$ (rather than its being eliminated by recombination) (Muyrers et al. 2001), but GMI1000 rarely gave rise to such mutants. Each cycle of mutagenesis required about 10 days, and 20 to $50 \%$ of the sucrose-tolerant tetracycline (Tc)sensitive colonies were the desired unmarked deletion mutant.

Some of the GMI1000 unmarked mutants lacking one or two pectic enzymes behaved as expected, but others did not exhibit the changes in virulence that were predicted based on prior results with $R$. solanacearum strains K60 and AW. Mutants lacking Pme and PehC retained the expected wild-type level of virulence (González and Allen 2003; Tans-Kersten et al. 1998), but mutants lacking either PehA, PehB, or PehA and PehB also presented near-wild type virulence. These results contrast with those in previous studies in which: i) mutants of K60 and AW lacking PehA were significantly less virulent than their wild-type parents, if the inoculum concentration was not too high (Denny et al. 1990; Huang and Allen 1997, 2000; Schell et al. 1988); ii) a mutant lacking PehB was consistently less virulent than K60 but more virulent than a mutant of this strain lacking PehA (Huang and Allen 1997, 2000); and iii) a double mutant lacking PehA and PehB that, in most assays, wilted about $50 \%$ of the leaves during a two-week assay, was the least virulent of the three (Huang and Allen 1997, 2000). Although GMI1000 and K60 are similarly virulent on tomato in our tests (not shown), the difference in virulence of their PehA, PehB, and PehA and PehB mutants may indicate that
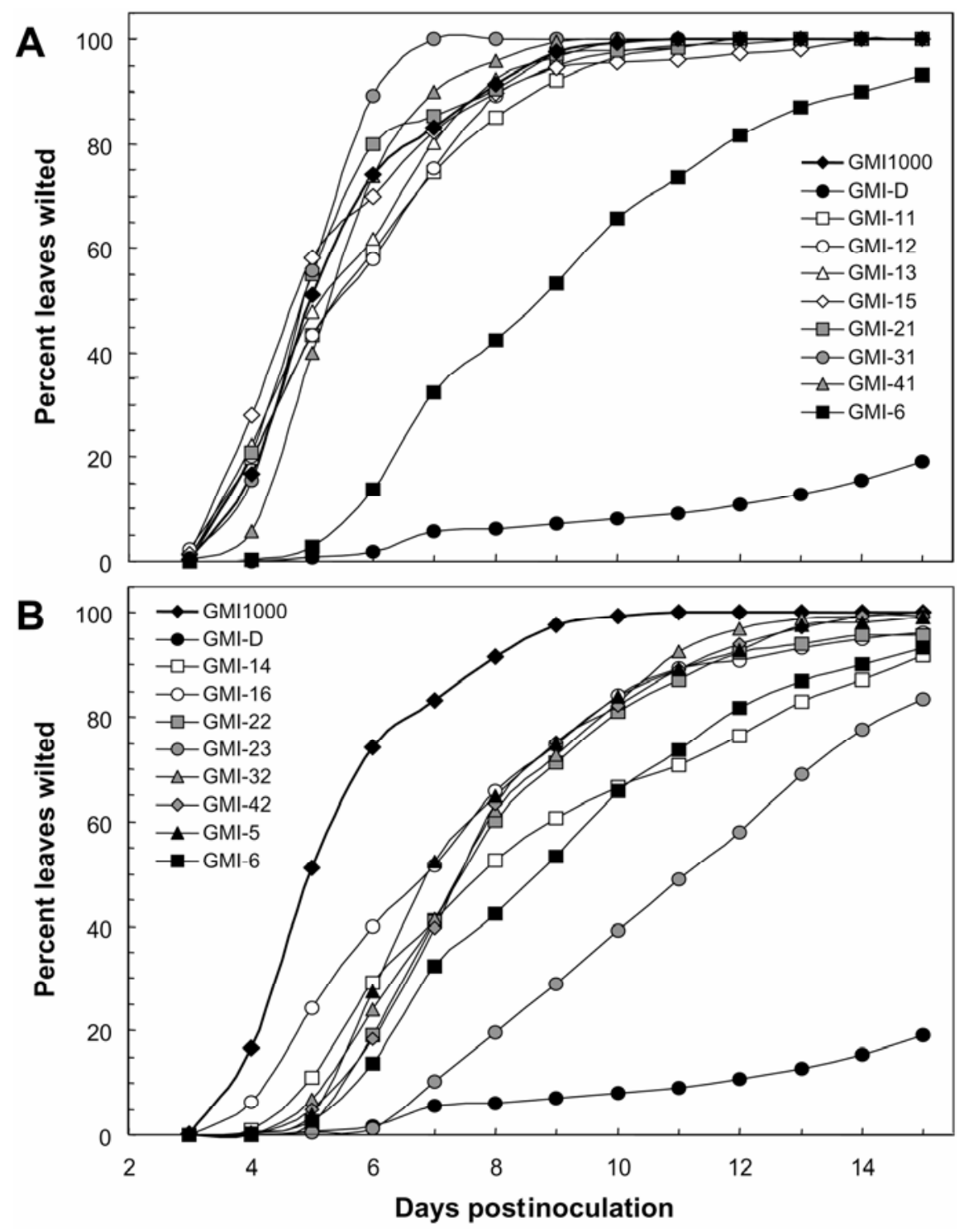

Fig. 5. Virulence of Ralstonia solanacearum GMI1000, GMI-D ( $s d p D:: p T o k 2)$, and 15 extracellular plant cell-wall-degrading enzyme mutants assessed using soil-drench inoculation. The average values from three to six independent assays of each strain are shown. The data for GMI1000, GMI-D, and GMI-6

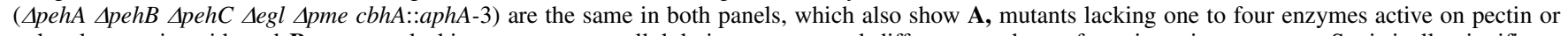
polygalacturonic acid, and B, mutants lacking one or two cellulolytic enzymes and different numbers of pectic active enzymes. Statistically significant differences in virulence were determined using a proportional hazards survival model. 
these strains differ in how much Peh activities contribute to pathogenesis. It is also possible that the reduced virulence of the marked mutants of AW and K60 was due to unintended side effects caused by expression of foreign antibiotic resistance genes or the production of truncated proteins from what remained of the ORF, because the peh genes were inactivated but not deleted.

The absence of all three Peh enzymes consistently resulted in a counterintuitive increase in virulence similar to that first observed by González and Allen (2003) for the mutant of K60 lacking PehA, PehB, and PehC. Unlike the K60 triple mutant, which was less virulent than its parent K60, eliminating the Peh enzymes created a strain, GMI-31, that was slightly more virulent than its parent GMI1000. We also observed increased virulence of the mutants lacking Egl and, most clearly, mutants lacking Egl and $\mathrm{CbhA}_{R s o l}$ when all three Peh enzymes also were eliminated (Fig. 5B, GMI-23 as compared with GMI-6). We have no better explanation of this phenomenon than that proposed by González and Allen (2003), who suggested that mutants lacking pectolytic enzymes do not generate biologically active pectic fragments from the plant cell walls that stimulate host resistance.

The significant reduction in virulence of the GMI1000 mutants lacking Egl (e.g., GMI-14) was similar to that observed previously for marked mutants of AW (Denny et al. 1990; Roberts et al. 1988). The precise role of the $R$. solanacearum Egl in wilt is not known. The enzyme has the large 'cellulase' motif (PFAM00150) that is typical of proteins in glycosyl hydrolase (GH) family 5 (CAZy website), but it lacks a carbohydrate-binding domain that is present in enzymes that attack microcrystaline cellulose. It is notable that $R$. solanacearum $\mathrm{Egl}$, like the endoglucanase from Macrophomina phaseolina, does not attack substrates smaller than cellopentose (Wang and Jones 1995). Together, these observations suggest that Egl partially degrades (loosens) primary cell walls. This activity contrasts with the more complete hydrolysis commonly caused by endoglucanases made by saprophytes.

Compared to the intensely studied Pel enzymes, there is relatively little known about the role of endoglucanases in diseases caused by other phytopathogenic bacteria. Both Pectobacterium carotovora and Erwinia chrysanthemi make one GH family 5 endoglucanase related to $R$. solanacearum $\mathrm{Egl}$ (CelV and CelZ, respectively), and a second, unrelated endoglucanase (CelB and CelY, respectively) (Toth et al. 2003). CelV but not CelB (GH family 12) contributes to virulence of Pectobacterium carotovora, whereas only CelY (GH family 8) contributes to the rate of soft rotting caused by Erwinia chrysanthemi, despite exhibiting low macerating ability in vitro. The genomic sequence of Pectobacterium carotovora subsp. atroseptica SCRI1043 (Bell et al. 2004) appears to have only CelV and CelB homologs (although annotated as a cellulase, ECA2220 lacks a catalytic domain). The genomic sequences of Xanthomonas axonopodis pv. citri, Xanthomonas campestris pv. campestris, and Xanthomonas oryzae pv. oryzae show that each has virtually the same set of potential GH family 5 enzymes. They all have three adjacent endoglucanases (65\% identical to each other) that are about $48 \%$ identical to the catalytic domain in $R$. solanacearum Egl. A fourth potential endoglucanase (EngXCA, unrelated to Egl) is present in all three species, and $X$. campestris pv. campestris and $X$. oryzae pv. oryzae have a fifth potential endoglucanase (EngXCA-like, also unrelated to Egl). Two strains of Xylella fastidiosa that have been completely sequenced have one $\mathrm{Egl}$ similar to $R$. solanacearum and two EngXCA-like endoglucanases similar to those in the xanthomonads. The role of these multiple cellulolytic enzymes in disease has not been reported, and progress in future studies will greatly benefit from our approach of pyramiding deletions.
The contribution of $\mathrm{CbhA}_{\text {Rsol }}$ to disease had not been studied previously, in part due to its exhibiting no easily detectable enzyme activity despite being secreted by GMI1000. Because $\mathrm{CbhA}_{R s o l}$ is a putative exoglucanase, we did not expect that it would be very important for virulence and were surprised to find that it contributed almost as much to disease as did the $\mathrm{Egl}$ endoglucanase. Our data suggest that $\mathrm{CbhA}_{\text {Rsol }}$ and $\mathrm{Egl}$ contribute additively to virulence of $R$. solanacearum, which contrasts with the synergistic activity observed in vitro when some bacterial and fungal exo- and endoglucanases are mixed at an appropriate ratio (Zhou and Ingram 2000).

Genin and Boucher (2002) noted that in GMI1000 cbhA has the features of a recently acquired gene. Our analysis of genomic sequences revealed that multiple nonphytopathogenic Ralstonia and Burkholderia species closely related to R. solanacearum lack a CbhA ortholog. There also appears to be no similar exoglucanase gene in $X$. axonopodis pv. citri, three Pseudomonas syringae pathovars, Pectobacterium carotovora, Erwinia chrysanthemi, or Pantoea stewartii that causes leaf spots or rots on various plants. In addition, no CbhA ortholog was found in either Leifsonia xyli subsp. xyli or Clavibacter michiganensis subsp. sepedonicus, two gram-positive phytopathogenic bacteria that colonize the xylem of sugar cane and potato, respectively. In contrast, $X$. fastidiosa (three strains), $X$. campestris pv. campestris, and $X$. oryzae pv. oryzae, all of which are vascular pathogens like $R$. solanacearum, appear to encode one or two orthologs that are $\geq 75 \%$ similar to $\mathrm{CbhA}_{\text {Rsol }}$. The hosts of these four gram-negative phytopathogens range from annuals to woody perennials and from dicots to monocots, suggesting that exoglucanase activity may be a general trait that promotes multiplication, movement, or both of gramnegative phytopathogens within the xylem.

Although GMI-6, which lacks all six CWDE, was significantly less virulent than GMI1000, it still wilted over $90 \%$ of the leaves on almost $97 \%$ of the 63 inoculated plants. That $R$. solanacearum lacking all known CWDE remains quite virulent is reminiscent of the results for Erwinia chrysanthemi, in which elimination of five Pels and one Peh (encoded by four loci) did not eliminate virulence of strain EC16 (Kelemu and Collmer 1993). This is the only other good example in which pyramiding mutations were used to investigate the role of multiple CWDE in phytopathogenesis and revealed a second set of previously undiscovered Pel enzymes. These plant-in-

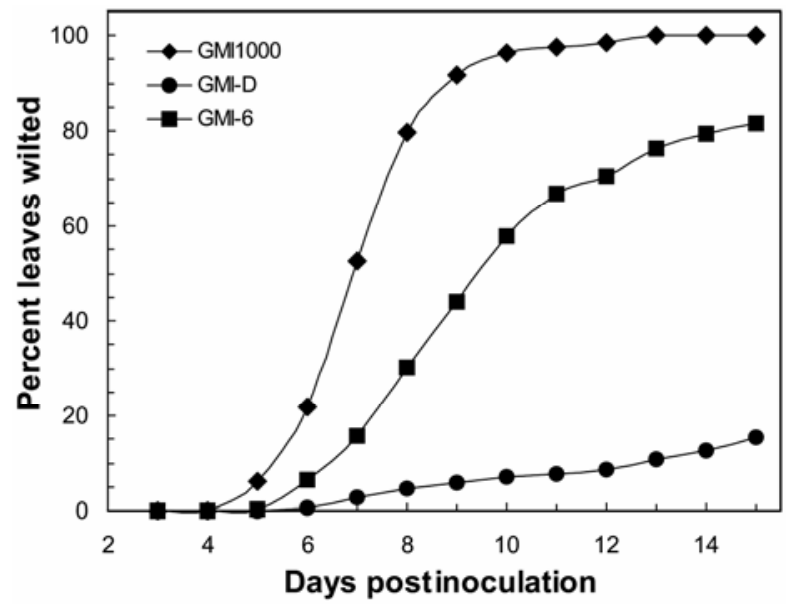

Fig. 6. Virulence of Ralstonia solanacearum GMI1000, GMI-D (sdpD::pTok2), and GMI-6 ( $\Delta p e h A \Delta p e h B \Delta p e h C \Delta e g l \Delta p m e$ cbhA::aphA$3)$ mutants assessed using wounded-petiole inoculation. The average values from three independent assays of each strain are shown. Statistically significant differences in virulence were determined using a proportional hazards survival model. 
ducible Pels could also be induced in culture by addition of plant extracts to the medium (Kelemu and Collmer 1993). We treated $R$. solanacearum cultures with similar plant extracts (Kelemu and Collmer 1993; Tans-Kersten et al. 1998) and saw no evidence of 'plant-inducible' CWDE when using standard enzyme substrates. There also appear to be no additional enzymes likely to attack pectic or cellulosic substrates in the GMI1000 genome (Genin and Boucher 2004; Salanoubat et al. 2002).

GMI-D, the T2SS mutant, exhibited much lower virulence than did any of the mutants specifically lacking CWDE after inoculation by either soil-drench or wounded-petiole methods. Soil drench is one of the most natural inoculation methods available because, to cause wilt disease, the pathogen must survive in the soil, migrate to a root, enter via a rare penetration site, and then systemically colonize the xylem. The application of inoculum directly to open xylem vessels of wounded petioles bypasses the soil survival, migration, and root penetration phases, and allows an assessment strictly of the colonization phase. Because the relative virulence of GMI1000, GMI6 , and GMI-D was comparable regardless of the inoculation method, this implies that the mutant's primary defect is a reduced ability to colonize tomato tissues after invasion. Furthermore, although the two cellulolytic enzymes are important for GMI1000 to wilt tomato plants, additional EXP secreted by the T2SS apparently contribute substantially to the ability of $R$. solanacearum to systemically colonize tomato plants.

\section{MATERIALS AND METHODS}

\section{Bacterial strains, plasmids and gene targets.}

Table 1 describes the strains, plasmids, and gene targets used to initiate this research. The $15 R$. solanacearum strains lacking one or more CWDE are described in Figure 3.

\section{Media and growth conditions.}

$R$. solanacearum was grown routinely in MBG broth $(0.5 \%$ Bacto peptone, $0.1 \%$ casamino acids, $0.1 \%$ yeast extracts, and $0.1 \%$ glucose) or on $\mathrm{MBG}$ agar (MBG broth $+1.6 \%$ agar [Sigma-Aldrich, St. Louis]) at $30^{\circ} \mathrm{C}$. The minimal medium was $\mathrm{MM} \pm 1.6 \%$ agar (Clough et al. 1994) or $3 \times$ MM (threefold more of all ingredients except glucose). Escherichia coli was incubated at $37^{\circ} \mathrm{C}$ in Luria-Bertani (LB) broth or LB + $1.6 \%$ agar (Miller 1972). The basal medium for exoenzyme assay plates contained liquid MM (without glucose), $0.1 \%$ yeast extract, $0.5 \%$ glycerol, and $1.6 \%$ agar. For Egl and Pme activities, the basal medium was supplemented with $1 \mathrm{mM} \mathrm{MgSO}_{4}$, $0.1 \mathrm{mM} \mathrm{CaCl}_{2}$, and, for Egl activity, $0.5 \%$ carboxymethylcellulose (Sigma) or, for Pme activity, $0.48 \%$ pectin (Sigma). For Peh activity, only $0.5 \%$ sodium polygalacturonate (Sigma) was added to the basal medium. MM agar with the glucose replaced by $0.5,1$, or $1.5 \%$ filter-sterilized sucrose was used for selecting $s a c B$ mutants that became sucrose tolerant. When desired, media were supplemented with ampicillin $\left(100 \mu \mathrm{g} \mathrm{m} \mathrm{m}^{-1}\right)$, kanamycin $\left(\mathrm{Km}, 50 \mu \mathrm{g} \mathrm{ml}^{-1}\right)$, or Tc $\left(5 \mu \mathrm{g} \mathrm{ml}^{-1}\right)$.

DNA manipulation, transformation, and sequence analysis. Cloning, competent cell preparation, electroporation, and heat-shock transformation of $E$. coli followed standard protocols (Ausubel et al. 1989). Plasmid DNA was isolated using a Qiagen mini kit (Qiagen Inc., Valencia, CA, U.S.A.). Isolation of $R$. solanacearum genomic DNA and natural transformation of $R$. solanacearum were described previously (Liu et al. 2001). Restriction enzymes and T4 DNA ligase were from New England Biolabs (Beverly, MA, U.S.A.). Unless noted, PCR used the MasterAmp Tfl DNA polymerase kit (Epicentre Technologies, Madison, WI, U.S.A.). PCR primer synthesis was performed at IDT (Coralville, IA, U.S.A.), and DNA sequencing was performed at the University of Georgia Integrated Biotechnology Laboratories (Athens, GA, U.S.A.).

\section{PCR reactions and plasmid construction.}

To prepare a plasmid for inactivating $s d p D$, an internal 750bp fragment (from nucleotide +606 to $+1,356$ ) was PCR-amplified and cloned into pCR2.1. The resulting plasmid was digested with $E c o$ RI to release the $s d p D$ fragment, which was then subcloned into similarly digested pTOK2 to create pCRsdpD'. To make a mutant allele of $c b h A$, a 1,260-bp fragment (from nucleotide +5 to $+1,265$ ) was PCR-amplified and cloned into pGEM-T Easy. The resulting plasmid was digested with EcoRV, which released a 159-bp fragment from within cbhA, and a 850-bp aphA-3 cassette was inserted in its place. The resulting approximately $2-\mathrm{kb}$ construct was released from the vector by digestion with EcoRI and was ligated to pEX18Tc to generate pECBH::aphA3.

Splice overlap extension (SOE) PCR (Horton et al. 1993) was used to make deletion alleles of five target genes. Briefly, four PCR primers (Table 2) were designed to amplify approximately 500-bp DNA fragments flanking each target in the GMI1000 genome. Along with the standard considerations for choosing PCR primer sites, we avoided removing DNA that might contain regulatory sequences for adjacent genes. PCR reactions used Easy-A high-fidelity polymerase (a proof-reading enzyme; Stratagene, La Jolla, CA, U.S.A.) according to the manufacturer's recommendations, except that each $50-\mu 1$ reaction contained $15 \mu \mathrm{l}$ of betaine enhancer (Epicenter Technologies). After each approximately 500-bp PCR product was cleaned, using a Qiagen PCR purification kit, appropriate pairs were mixed and a SOE PCR reaction joined them to produce an approximately 1.0-kb chimeric 'deletion allele'. For pehA, pehC, and pme deletion alleles, the upstream fragment contained the promoter but neither the native ribosome binding site nor the start codon, and the downstream fragment contained from 18 to 360 bases of the gene (presumably untranslated) and included the native stop codon. For the pehB deletion allele, the upstream fragment contained the promoter, ribosome binding site, start codon, and 11 bases of the native ORF, but a new stop codon within the SpeI site introduced between the upstream and downstream fragments terminates the ORF after only five amino acids. For the $e g l$ deletion allele, the modified ORF encodes a peptide containing eight $\mathrm{N}$-terminal and $70 \mathrm{C}$-terminal native amino acids, ending with the native stop codon.

The SOE products were cleaned using a PCR purification kit, were digested with $K p n \mathrm{I}$ and $X b a \mathrm{I}$ or HindIII and $X b a \mathrm{I}$, were resolved on an agarose gel, were recovered using a Qiagen gel purification kit, and were ligated to similarly digested pEX18Tc. This plasmid carries the levansucrase $s a c B$ gene that makes gram-negative bacteria grow poorly on sucrose. The plasmids containing deletion alleles were designated pSGA $(\triangle p e h A), \mathrm{pSGB}(\Delta p e h B), \mathrm{pSGC}(\Delta p e h C), \mathrm{pSEG}(\Delta e g l)$, and pSPM ( $\Delta p m e)$. Each deletion allele was confirmed by sequencing from the M13 forward and reverse primer sites in pEX18Tc.

\section{Creation of marked mutants.}

Plasmids pCRsdpD' and pECBH::aphA-3 were introduced into GMI1000 by electroporation, and transformants were selected on MBG Tc plates. Putative $s d p D$ mutants were selected, and insertion of pTOK2 into $s d p D$ was confirmed by PCR, using the $s d p D$-reverse primer and an M13 forward primer that anneals to vector sequences. Two Tc-resistant colonies that had pECBH::aphA-3 integrated into the genome were processed as described for the unmarked mutations (below), except that 50 colonies were patched onto an MBG Km plate instead of an 
enzyme-assay plate. A representative Tc-sensitive and $\mathrm{Km}$ resistant colony was selected as the $c b h A$ mutant, and inactivation of $c b h A$ was confirmed by PCR. The $c b h A:: a p h A-3$ allele was transferred site-specifically into other $R$. solanacearum strains by genomic transformation (Bertolla et al. 1997).

\section{Creation}

of unmarked mutants (SacB-assisted mutagenesis).

pSGA, pSGB, pSGC, pSEG, and pSPM were introduced into $R$. solanacearum by electroporation, and selection on MBG Tc plates yielded mutants in which a single homologous recombination event inserted the plasmid into the genome. Two single colonies from each transformation were recultured on the same medium, and then, bacteria were suspended in sterile water $\left(1 \times 10^{5} \mathrm{CFU} \mathrm{m}{ }^{-1}\right)$ and $0.1 \mathrm{ml}$ of the suspension was spread on each plate of MM with $0.5,1.0$, or $1.5 \%$ sucrose. After a 3-day incubation, 50 large mucoid colonies of each transformant were patched onto MBG plates and were incubated over night. The colonies were repatched onto MBG Tc plates and suitable exoenzyme assay plates and were incubated for $24 \mathrm{~h}$, at which time the assay plates were 'developed' with $2 \mathrm{M} \mathrm{HCl}$ (for Peh and Pme activity) or $0.1 \%$ Congo red and 1 $\mathrm{M} \mathrm{NaCl}$ (for Egl activity), as described previously (Roberts et al. 1988). Putative deletion mutants were Tc sensitive and were negative for enzyme activity. In most cases, the loss of PehB or PehC activity could not be detected using exoenzyme assay plates, so rapid diagnostic PCR was employed to detect deletion of the target gene. PCR templates were prepared by suspending about $5 \times 10^{7}$ bacteria of $10 \mathrm{Tc}$-sensitive colonies in $50 \mu \mathrm{l}$ each of sterile distilled water and heating the suspension at $100^{\circ} \mathrm{C}$ for $9 \mathrm{~min}$. One microliter of each sample was used in a standard PCR reaction that contained primer SOE4 and a diagnostic primer (Table 2) whose annealing site included the introduced SpeI site within the deletion allele. A selected PCRpositive colony was confirmed to be deletion mutant by PCR, using primers SOE1 and SOE4.

\section{Virulence assays.}

Virulence on tomato (Lycopersicon esculentum Mill., cultivar Marion) was assessed using a soil-drench method (Liu et al. 2001), except that plants were inoculated 3 weeks after transplanting (at the six- to seven-leaf stage), using bacteria that had been grown to stationary phase in $3 \times$ MM liquid medium. The cumulative number of leaves wilted on each plant was recorded daily for 15 days. To detect whether $R$. solanacearum had colonized plants not showing wilt symptoms, a $0.5-\mathrm{cm}$ stem section removed from just above the cotyledon node was soaked in $1 \mathrm{ml}$ of sterile deionized water for $1 \mathrm{~h}$ and was vortexed vigorously, and 20 - $\mu$ l samples were spotted on MBG Tc plates. Plates were examined for $R$. solanacearum colonies 1 and 2 days later. A wounded-petiole assay also was used to test selected strains (Liu et al. 2001).

The differences between the survival distributions of GMI1000 and the mutant strains were analyzed in SAS (version 8) using the PHREG and GENMOD procedures (Allison 1999). PHREG uses the Cox proportional hazards model to find the best-fitting nonparametric survival function $\left(\mathrm{S}_{\mathrm{t}}\right)$, with the hazard function $\mathrm{H}_{\mathrm{t}}=-\ln \mathrm{S}_{\mathrm{t}}$ for a selected baseline strain. Other strains are assumed to be proportional to the baseline hazard function. Analyses examined strain, date, and location effects. However, naive use of the PHREG model underestimates standard errors for the model coefficients, because it incorrectly assumes that leaves on each tomato plant behave

Table 2. Primers used in this study

\begin{tabular}{|c|c|c|}
\hline Gene target & Primer sequence $\left(5^{\prime} \rightarrow 3^{\prime}\right)^{\mathrm{a}}$ & Restriction site added \\
\hline \multirow[t]{5}{*}{ pehA } & SOE1: GACAAGCTTCACCGGGCATTACCTG & HindIII \\
\hline & SOE2: ACTAGTGGATCAGCAAAGCGACAG & SpeI \\
\hline & SOE3: TCGCTTTGCTGATCCACTAGTGCCGCTGAAGTCCGT & SpeI \\
\hline & SOE4: GACTCTAGACATGCCGGAAATCTATGC & $X b a \mathrm{I}$ \\
\hline & Primer S: ATCGCCGAGCTGATGCG & \\
\hline \multirow[t]{6}{*}{$\operatorname{peh} B$} & SOE1: GACAAGCTTGCGTTCGTCGGTCAAC & HindIII \\
\hline & SOE2: ACTAGTTTCTTTGTCGCATTGCAC & SpeI \\
\hline & SOE3: GCGACAAAGAAACTAGTGGCCCGGCGTCAATGA & SpeI \\
\hline & SOE4: GACTCTAGACAGGGCCACACGGTCGAT & $X b a \mathrm{I}$ \\
\hline & Primer S: GGTACCTTGCGACTG & \\
\hline & Primer D: ATGCGACAAAGAAACTAG & \\
\hline \multirow[t]{6}{*}{ pehC } & SOE1: GACAAGCTTCGGCAAGCTCTATCGC & HindIII \\
\hline & SOE2: ACTAGTAGGTTCAGGGTGAATCCA & SpeI \\
\hline & SOE3: САCСCTGAACCTACTAGTGACTACCAGCCGTCCAAG & SpeI \\
\hline & SOE4: GACTCTAGAGTACTGCTGCGTCGTGAT & $X b a \mathrm{I}$ \\
\hline & Primer S: GTGCCGGTGGCTAAG & \\
\hline & Primer D: ATTCACCCTGAACCTACTAG & \\
\hline \multirow[t]{5}{*}{$e g l$} & SOE1: GACGGTACCGCATGGCCGCCGTGAG & KpnI \\
\hline & SOE2: GAACTCGCCCAGGAAGCCACTAGTCATCGAAGCGGCAAC & SpeI \\
\hline & SOE3: ACTAGTGGCTTCCTGGGCGAGTTC & SpeI \\
\hline & SOE4: GACTCTAGACCGGTCCCGCTCGAAGTG & $X b a \mathrm{I}$ \\
\hline & Primer S: TGAATCAGGCAAATCCGG & \\
\hline \multirow[t]{6}{*}{ pme } & SOE1: GACGGTACCGAACGTCTTCGGTGATCT & KpnI \\
\hline & SOE2: ACTAGTGCTGGTGCGGTTGTAAT & SpeI \\
\hline & SOE3: CAACCGCACCAGCACTAGTGCGGGTAGCGGCAACTGA & SpeI \\
\hline & SOE4: GACTCTAGAGGCCGCACGACGAACTC & $X b a \mathrm{I}$ \\
\hline & Primer S: TCACTGGCCAGGCCGTAG & \\
\hline & Primer D: CAACCGCACCAGCACTAG & \\
\hline \multirow[t]{2}{*}{ cbhA } & Forward: CGCCTATCCAACATTATC & \\
\hline & Reverse: TTGTTCGGAATAAGTCTG & \\
\hline \multirow[t]{2}{*}{$s d p D$} & Forward: GCCCGCATCATCACCTCGAT & \\
\hline & Reverse: GCCCAGCTGCGACGCCTTGTC & \\
\hline
\end{tabular}

${ }^{\mathrm{a}} \mathrm{SOE}=$ splice overlap extension, Primer $\mathrm{S}=$ sequencing primer, Primer $\mathrm{D}=$ diagnostic polymerse chain reaction primer. Bold letters show restriction endonuclease recognition sequences. Italicized letters show homologous sequences between SOE2 and SOE3 primers necessary for SOE polymerase chain reaction. Primer pair SOE1 and SOE2 and pair SOE3 and SOE4 amplify upstream and downstream fragments, respectively. 
independently. In reality, wilting of a plant's first leaf greatly increases the likelihood of subsequent leaves wilting. Not correcting for this statistical 'overdispersion' would result in exaggerating the statistical differences between strains. Therefore, the correct (larger) standard errors of the model coefficients were estimated using the diagnostic statistics of GENMOD in conjunction with the 'D-Scale' option.

\section{Mutant characterization.}

To determine multiplication rates, all the strains were grown to approximately $1 \times 10^{9} \mathrm{CFU} \mathrm{ml}{ }^{-1}$ in $\mathrm{MBG}$ broth, were diluted to $2 \times 10^{7} \mathrm{CFU} \mathrm{ml} \mathrm{m}^{-1}$ in fresh MBG broth, and were shaken at $30^{\circ} \mathrm{C}$, and turbidity $\left(\mathrm{OD}_{600 \mathrm{~nm}}\right)$ was measured $16,18,20,22$, and $40 \mathrm{~h}$ later. Selected strains also were diluted to $4 \times 10^{3}$ $\mathrm{CFU} \mathrm{ml} \mathrm{m}^{-1}$ into liquid $\mathrm{MM}$ and were shaken at $30^{\circ} \mathrm{C}$, and viable cell counts were made $0,4,8,12,32,36$, and $48 \mathrm{~h}$ later. The concentration of extracellular polysaccharide in culture supernatants was determined as reported previously (Brumbley and Denny 1990). Twitching motility was tested on MBG plates as described by Liu and associates (2001). Swimming motility was evaluated by stabbing cells into motility agar (1\% tryptone, $0.3 \%$ agar) and measuring the zone of colonization after incubating for 3 days. Biofilm formation was examined by immersing sterile PVC strips in cultures that were incubated without shaking, as described by Kang and associates (2002). To examine total EXP, cells were removed from MM liquid cultures $\left(\mathrm{OD}_{600}=\right.$ approximately 1$)$ by centrifugation and filtration $(0.2-\mu \mathrm{m}$ pore membrane), proteins were precipitated from the supernatant by addition of trichloroacetic acid to a final concentration of $10 \%(\mathrm{vol} / \mathrm{vol})$, and the protein pellet was recovered by centrifugation. After the pellet was washed with ice-cold acetone, the proteins were dissolved in sample buffer and were resolved by SDS-PAGE on a Bio-Rad Ready Gel (Bio-Rad, Hercules, CA, U.S.A.) as described by the manufacturer. Gels were stained with silver nitrate (Blum et al. 1987). To test the ability of mutants to elicit a hypersensitive reaction, water suspensions of $1 \times 10^{7}$ and $1 \times 10^{8} \mathrm{CFU} \mathrm{ml} \mathrm{m}^{-1}$ were infiltrated to tobacco leaves as described previously (Liu et al. 2001).

\section{ACKNOWLEDGMENTS}

This work was supported by a grant from the National Science Foundation (MCB-0236497). We thank J. Wang and C. Rodriguez-Lother for their technical assistance and the University of Georgia Statistical Consulting Center for help with analysis of the virulence data.

\section{LITERATURE CITED}

Allison, P. D. 1999. Logistic Regression Using the SAS System: Theory and Applications. SAS Press, Cary, NC, U.S.A.

Altschul, S. F., Madden, T. L., Schäffer, A. A., Zhang, J., Zhang, Z., Webb, M., and Lipman, D. J. 1997. Gapped BLAST and PSI-BLAST: A new generation of protein database search programs. Nucleic Acids Res. 25:3389-3402.

Ausubel, F. M., Brent, R., Kingston, R. E., More, D. D., Seidman, J. G., Smith, J. A., and Struhl, K. 1989. Short Protocols in Molecular Biology. Green Publishing Assoc. and Wiley-Interscience, New York.

Bell, K. S., Sebaihia, M., Pritchard, L., Holden, M. T. G., Hyman, L. J., Holeva, M. C., Thomson, N. R., Bentley, S. D., Churcher, L. J. C. Mungall, K., Atkin, R., Bason, N., Brooks, K., Chillingworth, T., Clark, K., Doggett, J., Fraser, A., Hance, Z., Hauser, H., Jagels, K., Moule, S., Norbertczak, H., Ormond, D., Price, C., Quail, M. A., Sanders, M., Walker, D., Whitehead, S., Salmond, G. P. C., Birch, P. R. J., Parkhill, J., and Toth, I. K. 2004. Genome sequence of the enterobacterial phytopathogen Erwinia carotovora subsp. atroseptica and characterization of virulence factors. Proc. Natl. Acad. Sci. USA 101:11105-11110.

Bendtsen, J. D., Nielsen, H., von Heijne, G., and Brunak, S. 2004. Improved prediction of signal peptides: SignalP 3.0. J. Mol. Biol. 340:783795.

Bertolla, F., van Gijsegem, F., Nesme, X., and Simonet, P. 1997. Condi- tions for natural transformation of Ralstonia solanacearum. Appl. Environ. Microbiol. 63:4965-4968.

Blum, H., Beier, H., and Gross, H. J. 1987. Improved silver staining of plant proteins, RNA and DNA in polyacrylamide gels. Electrophoresis 8:93-99.

Brumbley, S. M., and Denny, T. P. 1990. Cloning of phcA from wild-type Pseudomonas solanacearum, a gene that when mutated alters expression of multiple traits that contribute to virulence. J. Bacteriol. 172:5677-5685.

Clough, S. J., Schell, M. A., and Denny, T. P. 1994. Evidence for involvement of a volatile extracellular factor in Pseudomonas solanacearum virulence gene expression. Mol. Plant-Microbe Interact. 7:621-630.

Coutinho, P. M. and Henrissat, B. 1999. Carbohydrate-active enzymes: An integrated database approach. Pages 3-12 in: Recent Advances in Carbohydrate Bioengineering. H. J. Gilbert, G. Davies, B. Henrissat, and B. Svensson, eds. The Royal Society of Chemistry, Cambridge.

Datsenko, K. A., and Wanner, B. L. 2000. One-step inactivation of chromosomal genes in Escherichia coli K-12 using PCR products. Proc. Natl. Acad. Sci. U.S.A. 6640-6645.

Delepelaire, P. and Wandersman, C. 2001. Protein export and secretion in gram-negative bacteria. Pages 165-208 in: Microbial Transport Systems. G. Winkelmann, ed. Wiley-VCH, Weinheim, Germany.

Denny, T. P., Carney, B. F., and Schell, M. A. 1990. Inactivation of multiple virulence genes reduces the ability of Pseudomonas solanacearum to cause wilt symptoms. Mol. Plant-Microbe Interact. 3:293-300.

Desvaux, M., Parham, N. J., Scott-Tucker, A., and Henderson, I. R. 2004. The general secretory pathway: A general misnomer? Trends Microbiol. 12:306-309.

Dums, F., Dow, J. M., and Daniels, M. J. 1991. Structural characterization of protein secretion genes of the bacterial phytopathogen Xanthomonas campestris pathovar campestris-Relatedness to secretion systems of other gram-negative bacteria. Mol. Gen. Genet. 229:357-364.

Fegan, M. and Prior, P. 2005. How complex is the Ralstonia solanacearum species complex? Pages 449-461 in: Bacterial Wilt: The Disease and the Ralstonia solanacearum Species Complex. C. Allen, P. Prior, and A. C. Hayward, eds. The American Phytopathology Society Press, St. Paul, MN, U.S.A.

Genin, S., and Boucher, C. 2002. Ralstonia solanacearum: Secrets of a major pathogen unveiled by analysis of its genome. Mol. Plant Pathol. 3:111-118.

Genin, S., and Boucher, C. 2004. Lessons learned from the genome analysis of Ralstonia solanacearum. Annu. Rev. Phytopathol. 42:107-134.

González, E. T., and Allen, C. 2003. Characterization of a Ralstonia solanacearum operon required for polygalacturonate degradation and uptake of galacturonic acid. Mol. Plant-Microbe Interact. 16:536-544.

Hayward, A. C. 2000. Ralstonia solanacearum. Pages 32-42 in: Encyclopedia of Microbiology, Vol. 4. J. Lederberg, ed. Academic Press, San Diego, CA

Hoang, T. T., Karkhoff-Schweizer, R. R., Kutchma, A. J., and Schweizer, H. P. 1998. A broad-host-range Flp-FRT recombination system for sitespecific excision of chromosomally-located DNA sequences: Application for isolation of unmarked Pseudomonas aeruginosa mutants. Gene 212:77-86.

Horton, R. M., Ho, S. N., Pullen, J. K., Hunt, H. D., Cai, Z. L., and Pease, L. R. 1993. Gene-splicing by overlap extension. Methods Enzymol 217:270-279.

Huang, Q., and Allen, C. 1997. An exo-poly- $\alpha$-D-galacturonosidase, PehB, is required for wild-type virulence of Ralstonia solanacearum. J. Bacteriol. 179:7369-7378.

Huang, Q., and Allen, C. 2000. Polygalacturonases are required for rapid colonization and full virulence of Ralstonia solanacearum on tomato plants. Physiol. Mol. Plant Pathol. 57:77-83.

Kang, Y., Huang, J. Z., Mao, G. Z., He, L. Y., and Schell, M. A. 1994. Dramatically reduced virulence of mutants of Pseudomonas solanacearum defective in export of extracellular proteins across the outer membrane. Mol. Plant-Microbe Interact. 7:370-377.

Kang, Y., Liu, H., Genin, S., Schell, M. A., and Denny, T. P. 2002. Ralstonia solanacearum requires type 4 pili to adhere to multiple surfaces, and for natural transformation and virulence. Mol. Microbiol. 46:427437.

Kelemu, S., and Collmer, A. 1993. Erwinia chrysanthemi EC16 produces a second set of plant-inducible pectate lyase isozymes. Appl. Environ. Microbiol. 59:1756-1761.

Kitten, T., and Willis, D. K. 1996. Suppression of a sensor kinase-dependent phenotype in Pseudomonas syringae by ribosomal proteins L35 and L20. J. Bacteriol. 178:1548-1555.

Lindeberg, M., and Collmer, A. 1992. Analysis of 8 out genes in a cluster required for pectic enzyme secretion by Erwinia chrysanthemi-Sequence comparison with secretion genes from other gram-negative bacteria. J. Bacteriol. 174:7385-7397. 
Liu, H., Kang, Y., Genin, S., Schell, M. A., and Denny, T. P. 2001. Twitching motility of Ralstonia solanacearum requires a type IV pilus system. Microbiology U.K. 147:3215-3229.

Meinke, A., Gilkes, N. R., Kwan, E., Kilburn, D. G., Warren, R. A. J., and Miller, R. C. 1994. Cellobiohydrolase A (CbhA) from the cellulolytic bacterium Cellulomonas fimi is a $\beta$-1,4-exocellobiohydrolase analogous to Trichoderma reesei Cbh II. Mol. Microbiol. 12:413-422.

Menard, R., Sansonetti, P. J., and Parsot, C. 1993. Nonpolar mutagenesis of the ipa genes defines IpaB, IpaC, and IpaD as effectors of Shigella flexneri entry into epithelial cells. J. Bacteriol. 175:5899-5906.

Miller, J. H. 1972. Experiments in molecular genetics. Cold Spring Harbor Laboratory Press, Cold Spring Harbor, NY, U.S.A.

Murphy, K. C., and Campellone, K. G. 2003. Lambda Red-mediated recombinogenic engineering of enterohemorrhagic and enteropathogenic E. coli. BMC Mol. Biol. 4:11.

Muyrers, J. P. P., Zhang, Y., and Stewart, A. F. 2001. Techniques: Recombinogenic engineering-New options for cloning and manipulating DNA. Trends. Biochem. Sci. 26:325-331.

Reyrat, J. M., Pelicic, V., Gicquel, B., and Rappuoli, R. 1998. Counterselectable markers: Untapped tools for bacterial genetics and pathogenesis. Infect. Immun. 66:4011-4017.

Roberts, D. P., Denny, T. P., and Schell, M. A. 1988. Cloning of the egl gene of Pseudomonas solanacearum and analysis of its role in phytopathogenicity. J. Bacteriol. 170:1445-1451.

Salanoubat, M., Genin, S., Artiguenave, F., Gouzy, J., Mangenot, S., Arlat, M., Billault, A., Brottier, P., Camus, J. C., Cattolico, L., Chandler, M., Choisne, N., Claudel-Renard, C., Cunnac, S., Demange, N., Gaspin, C., Lavie, M., Moisan, A., Robert, C., Saurin, W., Thébault, P., Schiex, T., Siguier, P., Whalen, M., Wincker, P., Levy, M., Weissenbach, J., and
Boucher, C. A. 2002. The genome sequence of the wide host-range plant pathogen Ralstonia solanacearum. Nature 415:497-502.

Sandkvist, M. 2001. Biology of type II secretion. Mol. Microbiol. 40:271283.

Schell, M. A. 2000. Control of virulence and pathogenicity genes of Ralstonia solanacearum by an elaborate sensory array. Annu. Rev. Phytopathol. 38:263-292.

Schell, M. A., Roberts, D. P., and Denny, T. P. 1988. Analysis of the Pseudomonas solanacearum polygalacturonase encoded by pglA and its involvement in phytopathogenicity. J. Bacteriol. 170:4501-4508.

Schweizer, H. P. 2003. Applications of the Saccharomyces cerevisiae FlpFRT system in bacterial genetics. J. Mol. Microbiol. Biotechnol. 5:67-77.

Tans-Kersten, J., Guan, Y. F., and Allen, C. 1998. Ralstonia solanacearum pectin methylesterase is required for growth on methylated pectin but not for bacterial wilt virulence. Appl. Environ. Microbiol. 64:4918-4923.

Toth, I. K., Bell, K. S., Holeva, M. C., and Birch, P. R. J. 2003. Soft rot erwiniae: From genes to genomes. Mol. Plant Pathol. 4:17-30.

Wang, H., and Jones, R. W. 1995. A unique endoglucanase-encoding gene cloned from the phytopathogenic fungus Macrophomina phaseolina. Appl. Environ. Microbiol. 61:2004-2006.

Zhou, S. G., and Ingram, L. O. 2000. Synergistic hydrolysis of carboxymethyl cellulose and acid-swollen cellulose by two endoglucanases (CelZ and CelY) from Erwinia chrysanthemi. J. Bacteriol. 182:5676-5682.

\section{AUTHOR-RECOMMENDED INTERNET RESOURCES}

Carbohydrate-Active Enzymes (CAZy) database: afmb.cnrs-mrs.fr/CAZY SignalP server: www.cbs.dtu.dk/services/SignalP 